FORMATION Formation emploi

Revue française de sciences sociales

100 | octobre-décembre 2007

De la formation professionnelle en Suisse

\title{
Une revue de référence ouverte à l'international
}

Jean-Frédéric Vergnies

\section{(2) OpenEdition}

Journals

Édition électronique

URL : http://journals.openedition.org/formationemploi/1249

DOI : 10.4000/formationemploi.1249

ISSN : 2107-0946

Éditeur

La Documentation française

Édition imprimée

Date de publication : 1 octobre 2007

Pagination : 1

ISSN : 0759-6340

Référence électronique

Jean-Frédéric Vergnies, « Une revue de référence ouverte à l'international », Formation emploi [En ligne],

100 | octobre-décembre 2007, mis en ligne le 23 septembre 2008, consulté le 30 octobre 2020. URL

http://journals.openedition.org/formationemploi/1249; DOI : https://doi.org/10.4000/

formationemploi. 1249 


\section{Éditorial}

\section{Une revue de référence ouverte à l'international}

e numéro 100 marque la pérennité de notre revue. Formation Emploi est devenue, au fil du temps, Formation Emploi, revue française de sciences sociales. Elle s'est régulièrement améliorée pour être aujourd'hui reconnue dans son domaine et référencée aussi bien dans les bases de données internationales comme le Journal of Economic Literature (JEL) ou le Social Sciences Citation Index (SSCI) que dans le classement des revues en économie et gestion du Cnrs. Nous fêterons l'anniversaire de la revue dans le numéro 101, consacré à des articles de synthèse sur les grands thèmes traités dans la revue et rédigés par des spécialistes émérites.

Dédié à la formation professionnelle en Suisse, ce numéro 100 participe de l'ouverture internationale de la revue. Il permettra aux lecteurs, notamment français, de retrouver les défis récurrents de la formation professionnelle et d'apprécier les spécificités du système suisse et, en écho, celles du système français.

Deux articles, l'un de Jonas Masdonati, Nadia Lamamra, Benoît Gay-des-Combes et Jacqueline De Puy sur les enjeux identitaires de la formation professionnelle, l'autre de Laurence Marti sur la qualification ouvrière, évoquent les défis du système de formation initiale duale, souvent perçu en France comme une panacée.

À l'inverse, dans le domaine de la formation continue, dans le secteur privé (Siegfried Hanhart) comme dans le secteur public (Yves Emery), certaines pratiques françaises peuvent être évoquées pour relever les défis existants en Suisse.

Pour leur part, Romain Felli, Gaële Goastellec et Jean-Philippe Leresche analysent les relations entre les systèmes de formation supérieure suisse et français en s'interrogeant sur l'existence d'un marché académique franco-suisse.

Enfin, la mise en œuvre de la formation professionnelle destinée aux chômeurs en Suisse (Olivier Giraud) est l'objet, dans les territoires, d'enjeux voire de conflits d'interprétation qui interpellent le lecteur français à l'heure d'une décentralisation de plus en plus large.

Hors dossier, Gilles Jeannot interroge la territorialité au travers de la construction des référentiels métier des agents de développement local. Il constate le décalage entre ces référentiels et la réalité du travail sur le terrain.

Bonne lecture et rendez-vous au numéro 101 ! 